\title{
Formulation and Evaluation of Ranitidine Hydrochloride Loaded Floating Microspheres for the Treatment of Gastric Ulcer
}

\author{
Manikandan Palanivelu', Aswathi Prashob², Nethaji Ramalingam ${ }^{3}$, Surendra Kumar Muniyandi ${ }^{4}$ \\ ${ }^{1}$ Professor \& Head Department of Pharmaceutics, Senghundhar college of Pharmacy, Kuraramangalam (po), Tiruchengode, \\ Tamilnadu, India -637205. \\ ${ }^{2,3}$ Department of Pharmaceutics, Devaki Amma Memorial College of Pharmacy, Chelembra, Malappuram (Dt), Kerala, India. - \\ 673634. \\ ${ }^{4}$ Department of Pharmacognosy, Senghundhar college of Pharmacy, Kuraramangalam (po), Tiruchengode, Tamilnadu, India - \\ 637205 .
}

\begin{abstract}
The study was aimed to prepare gastro retentive floating microsphere of Ranitidine Hydrochloride by Ionotropic Gelation technique and solvent evaporation technique by using the different carriers' ratios (Carbopol 934, Chitosan, and sodium alginate). Both natural and synthetic polymers have been used to prepare floating microspheres and evaluated the relevant parameters. There was no drug and carrier interactions assessed from FTIR. Depending upon the ratio, the percentage yield was found between $58.33 \%$ to $90.38 \%$. in all formulations. The surface morphology of microspheres was characterized by SEM and it was discrete, spherical in shape with rough outer surface and showed free flowing properties. The mean particle size of microspheres significantly increases with increasing polymer concentration and the range between $99.92 \pm 1.221$ to $168.23 \pm 1.963 \mu \mathrm{m}$. Among all the formulations, RF3 showed high drug entrapment efficiency (87.52\%). The percentage in-vitro buoyancy of the floating microspheres was in the range of $66.92 \%$ to $81.52 \%$. The in-vitro drug release study revealed that RF3, RF6 and RF9 Formulations having $89.97 \%, 92.91 \%, 93.68 \%$ drug released at the end of dissolution studies respectively. It could be concluded that the developed floating microsphere of Ranitidine Hydrochloride can be used for prolonged release in stomach. Therefore improving the bioavailability and patient compliance.
\end{abstract}

KEYWORDS: Chitosan, Carbopol 934, Floating Microspheres, Ionotropic Gelation Method, In-Vitro Drug Release, Ranitidine Hydrochloride, Sodium Alginate, Solvent Evaporation Method, Stability Studies.

\section{INTRODUCTION}

Oral drug delivery has been known for decades as the most widely used route of administration among all the routes that have been discovered for the systemic delivery. All controlled release systems have limited applications if the systems cannot remain in the area of the absorption site [1]. The controlled release drug delivery system possessing the ability of being retained in the stomach is called gastro retentive drug delivery system. They can help in optimizing the oral controlled delivery of drug having "absorption window" continually releasing the drug prior to absorption window for prolong period of time, thus ensuring optimal bioavailability [2]. Floating systems are low density systems that have maximum buoyancy to float on the gastric material and remain in the stomach for longer period of time. During the system hangover the gastric contents, the drug is released sustain with desired rate, which results in elevated gastric retention time and minimizes fluctuation also. A low amount of gastric content is required to permit the right achievement of the buoyancy retention principle, a minimal level of floating force $(F)$ is required to stay the dosage form buoyant on the surface of the gastric content. A floating dosage form is a feasible approach especially for drugs which have limited absorption sites in upper small intestine. The controlled, slow delivery of drug to the stomach provides sufficient local therapeutic levels and limits the systemic exposure to the drug [3.4].

Floating microspheres are especially useful in the delivery of such drugs and provides continuous, controlled administration of drug at the absorption site. For drugs with relatively short half-life, sustained release of the drug into the gastrointestinal tract maintain an effective concentration of drug in the systemic circulation for a long time and result in a flip-flop pharmacokinetics. So, formulating floating microspheres for short half-life drugs shows good therapeutic effect [5]. 


\section{International Journal of Current Science Research and Review}

ISSN: 2581-8341

Volume 04 Issue 08 August 2021

DOI: 10.47191/ijcsrr/V4-i8-01, Impact Factor: 5.825

IJCSRR@ 2021

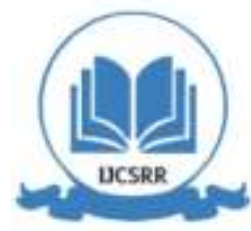

www.ijcsrr.org

Ranitidine hydrochloride, a histamine H2-receptor antagonist is widely prescribed and commonly used in active duodenal ulcers, gastric ulcers, Zollinger-Ellison syndrome, gastro oesophageal reflux disease and erosive esophagitis. The recommended adult dose of Ranitidine is $150 \mathrm{mg}$ twice daily or $300 \mathrm{mg}$ once daily. It also has a short biological half-life ( $2 \mathrm{hrs}$ ). Ranitidine $\mathrm{HCl}$ is absorbed only in the initial part of the small intestine and in all the above-mentioned ulcers, the disease is in the stomach and upper part of GIT. It has an absolute oral bioavailability of only $50 \%$. Colonic metabolism of Ranitidine $\mathrm{HCl}$ is partly responsible for its poor bioavailability [6]. These properties do not favour a traditional approach to sustained release delivery. In the present investigation efforts were made to formulate floating microspheres of Ranitidine Hcl to improve the absorption of Ranitidine in stomach, to prepare spherical floating microspheres, to study sustained effect of floating microspheres, to study the effect of different polymers on buoyancy and \% drug release. The relief of gastric-acid related symptoms can occur as soon as 60 minutes after administration of a single dose, and the effects can last from 4-10 hours, providing fast and effective symptomatic relief [7].

\section{MATERIALS AND METHODS}

Materials used

Ranitidine Hcl gift sample obtained from Medrich pharma Bengaluru, Carbopol 934, Chitosan, and sodium alginate obtained from Lobachemi, Pvt Ltd. Mumbai, Dichloro methane obtained from Qualigens Fine Chem Pvt Ltd, Mumbai, Calcium carbonate obtained from Qualikems fine chem. Pvt ltd, New Delhi Tween 80 obtained from Qualigens Fine Chem Pvt Ltd, Mumbai. Glacial acetic acid obtained from Medilise chemicals Kannur. Conc Hydrochloric acid obtained from Flora chemicals, Mumbai Potassium bromide obtained from Flora chemicals Mumbai.

\section{Methods}

Pre-formulation Studies

Compatibility Studies- Drug Polymer Interaction (FTIR Studies)

The FT-IR spectrum of Ranitidine hydrochloride and polymers was recorded using $\mathrm{KBr}$ mixing method on the FT-IR instrument (Schimadzu FTIR instrument). The drug alone, and in combination with polymers (mixed in the ratio of 1:1) was taken and subjected to FT-IR studies [8]

\section{Preparation of ranitidine Floating Microspheres \\ Method -1}

Floating microsphere of Ranitidine Hydrochloride was prepared by Ionotropic Gelation technique using different proportion of polymers (Chitosan and Carbopol 934). Sodium alginate dissolve in distilled water at a concentration of 2\% (w/v), the solution is stirring thoroughly after Ranitidine hydrochloride of different ratio and calcium carbonate is added. The Gelation medium is prepared by dissolving calcium chloride $(3 \% \mathrm{w} / \mathrm{v})$ in $2 \%$ glacial acetic acid. The homogenous alginate solution is extruding using $21 \mathrm{G}$ syringe needle into the Gelation medium. The distance between the edge of the needle and surface of Gelation medium is about $10 \mathrm{cms}$. The gel microspheres formed is left in the solution with gentle stirring for $30 \mathrm{~min}$ at room temperature to improve mechanic strength. After that, microspheres were collected and wash with distilled water twice, dried at room temperature for 24 hrs. and will store in desiccator. [9]

\section{Method-2}

The floating microsphere of Ranitidine Hcl was prepared by solvent evaporation (oil in water emulsion) technique. Ranitidine hydrochloride, Carbopol 934, Chitosan (1:1) were dissolved in a mixture of dichloromethane and ethanol (1:1) at room temperature. This was poured into $250 \mathrm{ml}$ water containing $0.02 \%$ Tween 80 maintained at a temperature of $30-40^{\circ} \mathrm{c}$ and subsequently stirred at a ranging agitation speed for $20 \mathrm{~min}$ to allow the volatile solvent to evaporate. The formed microspheres were filtered, washed with distilled water several time and dried in vacuum. [10]

Table No: 1 Composition of Ranitidine floating microsphere; Ionotropic Gelation method

\begin{tabular}{|c|c|c|c|c|c|c|c|c|}
\hline \multirow{2}{*}{$\begin{array}{l}\text { Formulation } \\
\text { code }\end{array}$} & \multirow{2}{*}{$\begin{array}{l}\text { Drug } \\
\text { dose } \\
(\mathrm{mg})\end{array}$} & \multirow{2}{*}{$\begin{array}{l}\text { Drug \& } \\
\text { polymer } \\
\text { ratio }\end{array}$} & \multicolumn{2}{|l|}{ Polymers } & \multirow{2}{*}{$\begin{array}{l}\text { Sodium } \\
\text { alginate } \\
(\mathrm{gm})\end{array}$} & \multirow{2}{*}{$\begin{array}{l}\text { Calcium } \\
\text { carbonate } \\
(\mathrm{mg})\end{array}$} & \multirow{2}{*}{$\begin{array}{l}\text { Calcium } \\
\text { chloride } \\
(\mathrm{gm})\end{array}$} & \multirow{2}{*}{$\begin{array}{l}\text { Glacial } \\
\text { acetic } \\
\text { acid (ml) }\end{array}$} \\
\hline & & & $\begin{array}{l}\text { Carpobol } \\
934(\mathrm{mg})\end{array}$ & $\begin{array}{l}\text { Chitosan } \\
(\mathrm{mg})\end{array}$ & & & & \\
\hline RF1 & 150 & $1: 4$ & 600 & - & 2 & 600 & 3 & 2 \\
\hline
\end{tabular}




\section{International Journal of Current Science Research and Review}

ISSN: 2581-8341

Volume 04 Issue 08 August 2021

DOI: 10.47191/ijcsrr/V4-i8-01, Impact Factor: 5.825

IJCSRR@ 2021

www.ijcsrr.org

\begin{tabular}{|l|l|l|l|l|l|l|l|l|}
\hline RF2 & 150 & $1: 5$ & 750 & - & 2 & 750 & 3 & 2 \\
\hline RF3 & 150 & $1: 6$ & 900 & - & 2 & 900 & 3 & 2 \\
\hline RF4 & 150 & $1: 4$ & - & 600 & 2 & 600 & 3 & 2 \\
\hline RF5 & 150 & $1: 5$ & - & 750 & 2 & 750 & 3 & 2 \\
\hline RF6 & 150 & $1: 6$ & - & 900 & & 900 & 3 & 2 \\
\hline
\end{tabular}

Table No. 2: Composition of Ranitidine floating microsphere; Solvent evaporation method

\begin{tabular}{|l|l|l|l|l|l|}
\hline & Drug dose $(\mathrm{mg})$ & $\begin{array}{l}\text { Drug \& Polymer } \\
\text { Ratio }\end{array}$ & $\begin{array}{l}\text { Chitosan } \\
(\mathrm{mg})\end{array}$ & $\begin{array}{l}\text { Dichloromethane \& Ethanol } \\
(1: 1 \text { ratio ml })\end{array}$ & Tween 80 (ml) \\
\hline RF7 & 150 & $1: 4$ & 600 & 10 & 0.2 \\
\hline RF8 & 150 & $1: 5$ & 750 & 10 & 0.2 \\
\hline RF9 & 150 & $1: 6$ & 900 & 10 & 0.2 \\
\hline
\end{tabular}

Evaluation parameters of ranitidine hydrochloride floating microspheres

\section{Percentage Yield}

The prepared microspheres were collected, dried at room temperature and then weighed. The measured weight of prepared microspheres was divided by the total amount of all excipient and drug used in the preparation of microspheres which will give the total percentage yield of floating microspheres [11].

The amount of microspheres obtained $(\mathrm{g})$

Percentage yield $(\%)=$

X 100

Theoretical amount $(\mathrm{g})$

\section{Determination of Particle Size}

The size of the prepared floating microspheres was measured by an optical microscopy method (Olympus, India) fitted with eye piece micrometer which was then calibrated with stage micrometer.

Procedure: Calibrate the eye piece micrometer and transfer the microspheres on clean slide. Add one or two drops of liquid paraffin. Dispense the sample uniformly with the help of a brush. Place the cover slip to avoid entrapment of air bubbles. Drain the excess liquid with a blotting paper. Place the slide on the stage of the microscope. Focus the slide in low magnification (10X), observe the presence of individual particle. Shift to high power (45X) and focus the slide. Measure the size of each particle in terms of eye piece divisions. Tabulate the particle in terms of division of eye piece and number of particles. Multiply the number of eye piece divisions by the calibrated values. Classify the diameters in to size ranges and calculate the number of divisions. The average mean size was calculated by retrieving the size of about 100 microspheres from each batch was determined by the given equation(s).[12]

\section{No: of division on stage micrometer}

\section{Calibration factor $=$}

\section{No: of division on eye piece micrometer}

Size of individual particle $(\mu \mathrm{m})=$ Number of division on eyepiece $\times$ Calibration factor

Average particle size $(\mu \mathrm{m}) \quad=$ Sum of individual particle $/ 100$

\section{Morphological Studies (SEM)}

In general, SEM has been used to determine particle size distribution, surface topography, texture, fractured surface/sectioned surface and characterizing drug delivery system, owing in large simplicity of sample preparation and ease of operation. The best formulation were taken for the surface characterization. For the external morphology studies, the microspheres were visualized using scanning electron microscopy (SEM, JEOL JSM-6701 F, JAPAN) operating at 15KV. The samples were mounted on electron microscope brass stub and coated with in an ion sputter, under vacuum. The shape and surface characteristic of floating microspheres were taken by random scanning of the stub and photomicrographs [13] 


\section{International Journal of Current Science Research and Review}

ISSN: 2581-8341

Volume 04 Issue 08 August 2021

DOI: 10.47191/ijcsrr/V4-i8-01, Impact Factor: 5.825

IJCSRR@ 2021

Www.ijcsrr.org

\section{Micromeritic Properties}

The characterization of prepared microspheres was carried out by particle size, angle of repose, bulk density, tapped density, and Carr's index [14]

\section{Entrapment Efficiency (EE)}

An accurately weighed microsphere $(100 \mathrm{mg})$ was taken and triturated with $50 \mathrm{ml} 0.1 \mathrm{~N} \mathrm{HCl}$ and filtered to remove debris. Volume was made up to $100 \mathrm{ml}$ with $0.1 \mathrm{~N} \mathrm{HCl}$ and diluted suitably before the recording of absorbance at $315 \mathrm{~nm}$ using uv spectrophotometer [15].

The drug EE was calculated using the following formula.

Estimated percent drug content

(Amount of drug actually present)

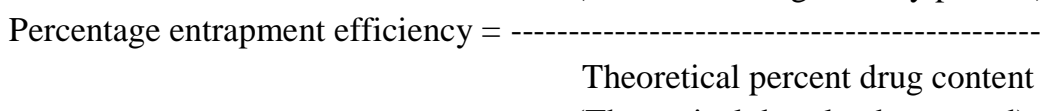

X 100

(Theoretical drug load expected)

\section{In-vitro Buoyancy Studies}

An accurately weighed $100 \mathrm{mg}$ drug equivalent floating microsphere was taken for in-vitro buoyancy study. The selected number of microspheres were spread over $900 \mathrm{ml}$ simulated gastric fluid $(\mathrm{pH} 1.2)$ containing $0.02 \% \mathrm{~W} / \mathrm{V}$ Tween 80 in dissolution apparatus (USP, type-II) agitating at 100rpm. At the end of $12 \mathrm{hrs} \mathrm{the} \mathrm{buoyant} \mathrm{microspheres} \mathrm{were} \mathrm{pipette} \mathrm{out} \mathrm{and} \mathrm{separated} \mathrm{by} \mathrm{filtration,}$ particles in the sinking particulate layer were also separated by filtration. Particles of both types were dried in desiccators. Both the fraction of microspheres was weighed and buoyancy was determined by following equation [ [16].

$$
\text { Buoyancy percentage }=\frac{W_{\mathrm{f}} \mathrm{X} 100}{--\mathrm{W}_{\mathrm{f}}+\mathrm{Ws}_{\mathrm{s}}}
$$

Where $\mathrm{W}_{\mathrm{f}}$ and $\mathrm{Ws}$ are the weight of the floating and settled microspheres respectively.

\section{In-vitro Drug Release Studies}

The in-vitro drug release studies were conducted in gastric $\mathrm{pH}$ using paddle type dissolution apparatus under sink conditions. Accurately weighed samples of the microspheres was taken into $900 \mathrm{ml}$ of dissolution medium (pH 1.2) maintained at $37 \pm 0.50 \mathrm{C}$ with paddle rotating at 100rpm. The adequate samples were withdrawn every $1 \mathrm{hrs}$ up to $12 \mathrm{hrs}$ and the same volume of fresh medium was refilled for maintaining the sink condition. The withdrawn samples were filtered through Whatman filter paper. After suitable dilution, the samples are analysed spectrophotometrically at $315 \mathrm{~nm}$. The dissolution studies were carried out in triplicate and the percentage drug release was calculated and the graph was considered between cumulative percentage drug release and time in hours [17].

\section{Kinetics Analysis of in-vitro Drug Release Studies}

To examine the drug release kinetics and mechanism, the cumulative release data were fitted to models representing Zero order $(\mathrm{Q}$ Vs t), First order [Log (Q0-Q) Vs t], Higuchi's square root of time (Q Vs t1/2) and Korsmeyer-Peppa's (Log Q Vs Log t) respectively, where $\mathrm{Q}$ is the cumulative percentage of drug released at time $t$ and $(\mathrm{Q} 0-\mathrm{Q})$ is the cumulative percentage of drug remaining after time $t$. In short the results obtained from in-vitro release studies were plotted in four kinetic models of data treatment. Generally, on the basis of the diffusion exponent, an " $n$ " value of 0.5 or less than 0.5 indicates the drug release mechanism approaches to a Fickian diffusion-controlled release, where as " $n$ " value from 0.5 to 1 indicates the drug release mechanism is NonFickian diffusion [18].

\section{Stability Studies}

From the prepared floating microspheres which showed appropriate balance between the buoyancy and the in-vitro percentage drug release was selected for stability studies. The selected best formulations were placed in borosilicate screw capped glass containers and stored in different temperatures like room temperature $(27 \pm 20 \mathrm{C}, 60 \pm 5 \% \mathrm{RH})$ and stability chamber $(45 \pm 20 \mathrm{C}, 70 \pm 5 \% \mathrm{RH})$. At the end of 30, 60, 90 days period, samples were withdrawn and the microspheres are analysed for their drug content [19,20]. 


\section{International Journal of Current Science Research and Review}

ISSN: 2581-8341

Volume 04 Issue 08 August 2021

DOI: 10.47191/ijcsrr/V4-i8-01, Impact Factor: 5.825

IJCSRR@ 2021

www.ijesrr.org

\section{RESULTS AND DISCUSSION}

Pre-formulation Studies

Compatibility Studies - Fourier transforms infrared spectroscopy (FTIR)

Peak Find - RAN+HcL

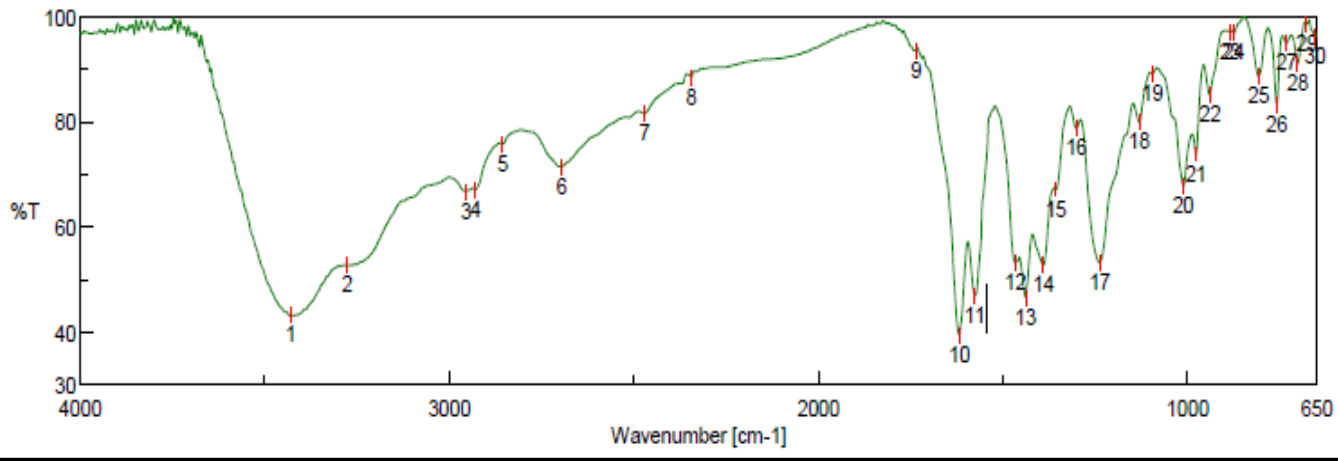

Fig.no. 1: IR spectra of pure Ranitidine Hydrochloride

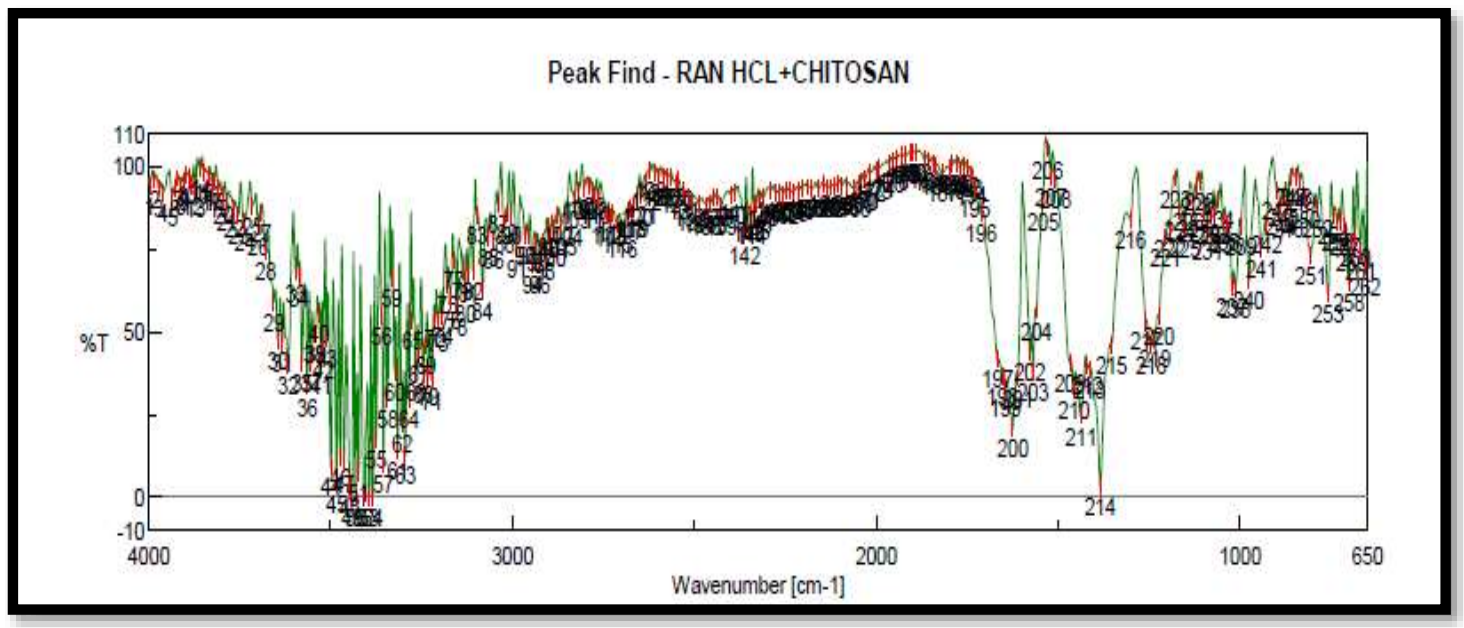

Fig.no. 2: IR Spectra Studies of Physical Admixtures of Ranitidine hydrochloride and Chitosan

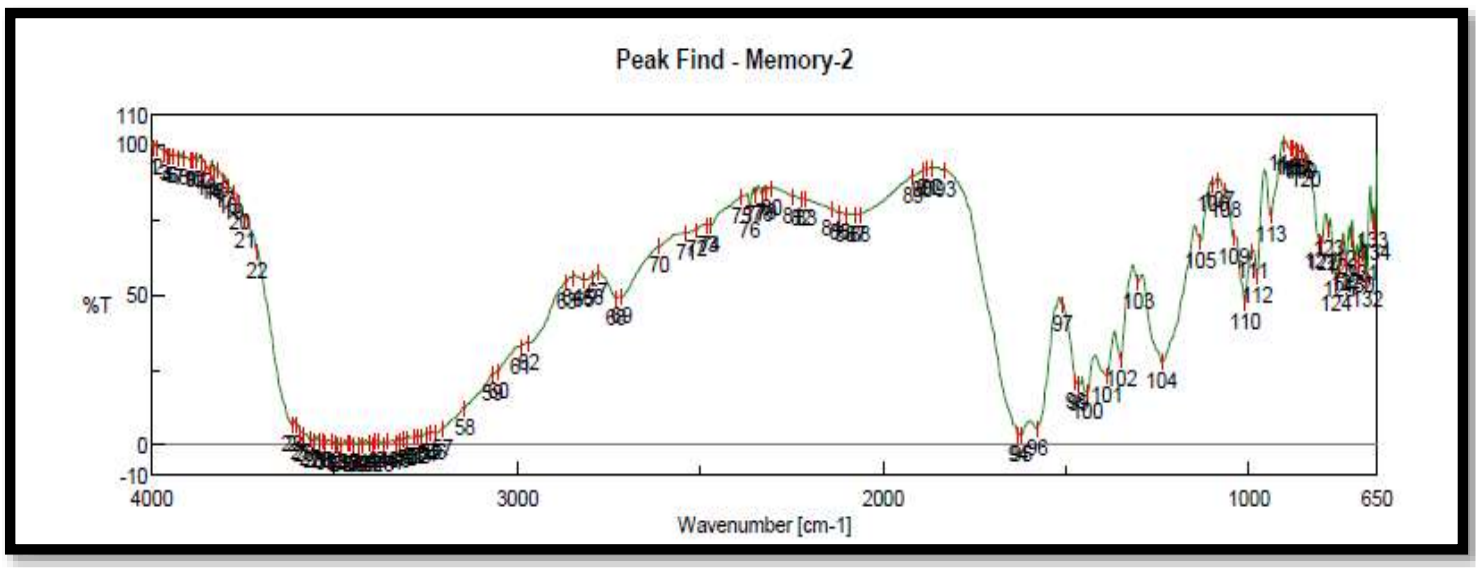

Fig no. 3: IR Spectra Studies of Physical Admixtures of Ranitidine hydrochloride and Carbopol 934 


\section{International Journal of Current Science Research and Review}

ISSN: 2581-8341

Volume 04 Issue 08 August 2021

DOI: 10.47191/ijcsrr/V4-i8-01, Impact Factor: 5.825

IJCSRR@ 2021

www.ijjcsrr.org

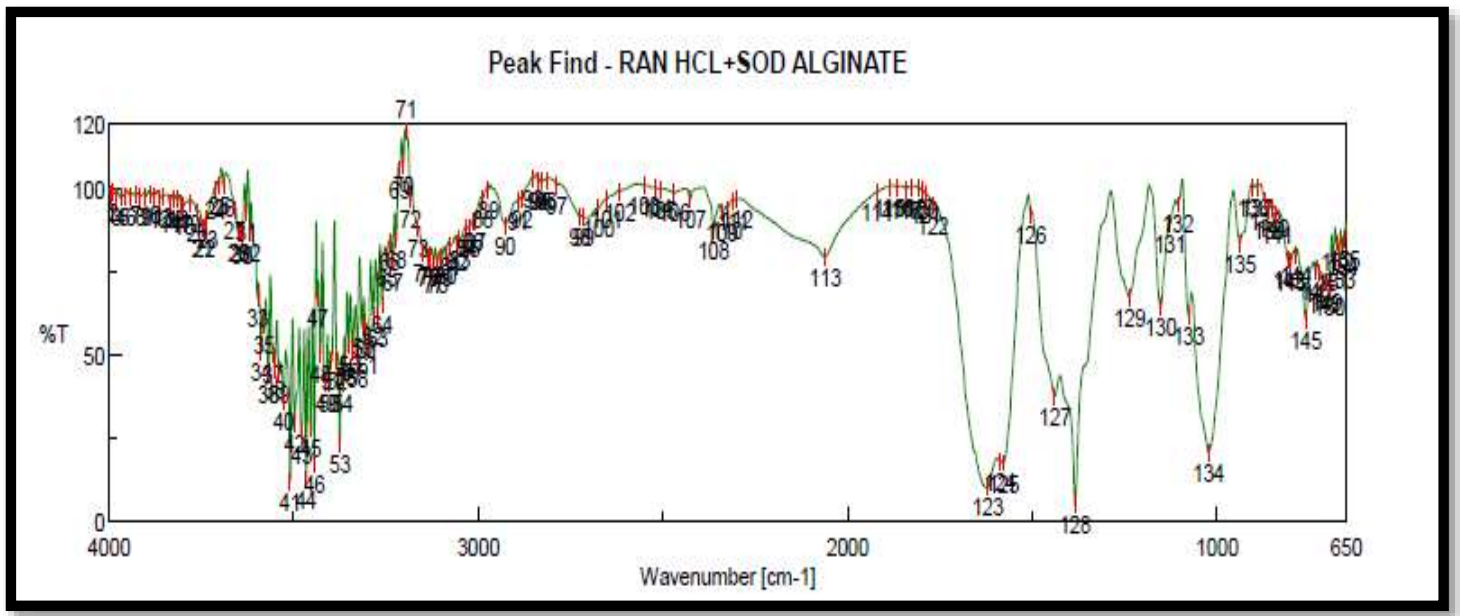

Fig.no 4: IR Spectra Studies of Physical Admixtures of Ranitidine hydrochloride and Sodium Alginate

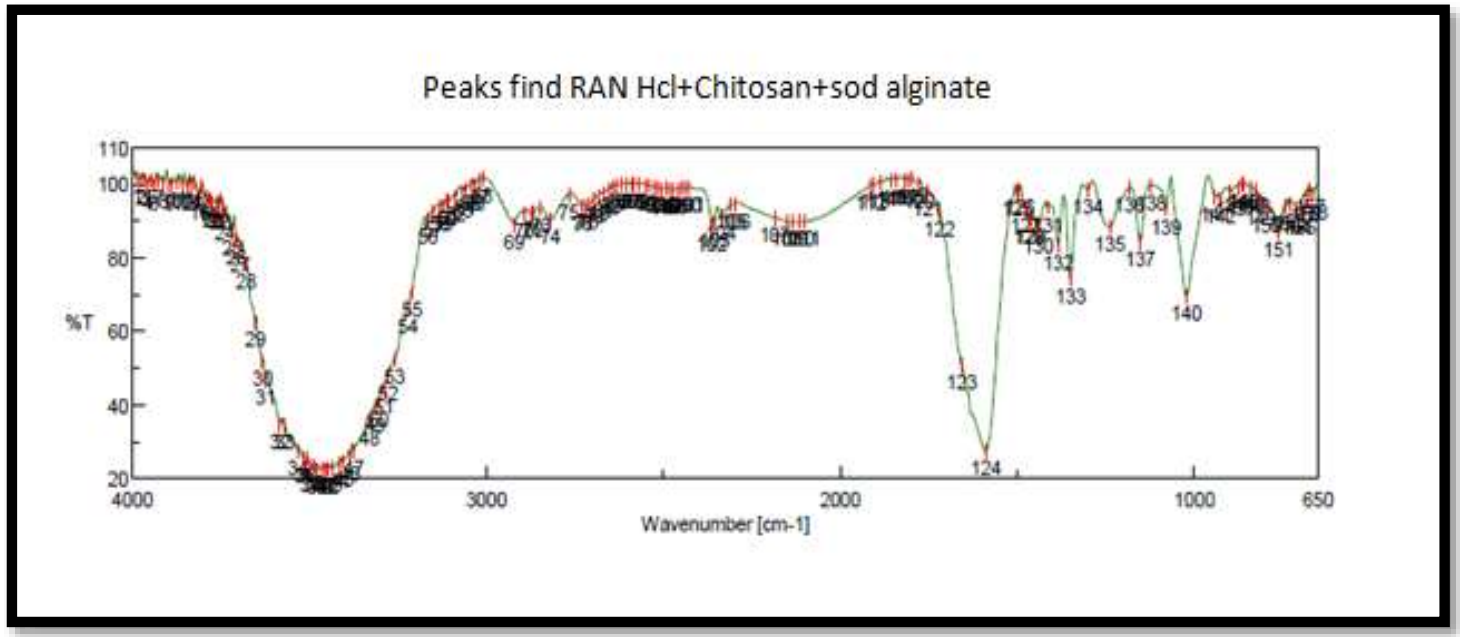

Fig.no 5: IR Spectra Studies of Physical Admixtures of Ranitidine hydrochloride, Chitosan and Sodium Alginate.

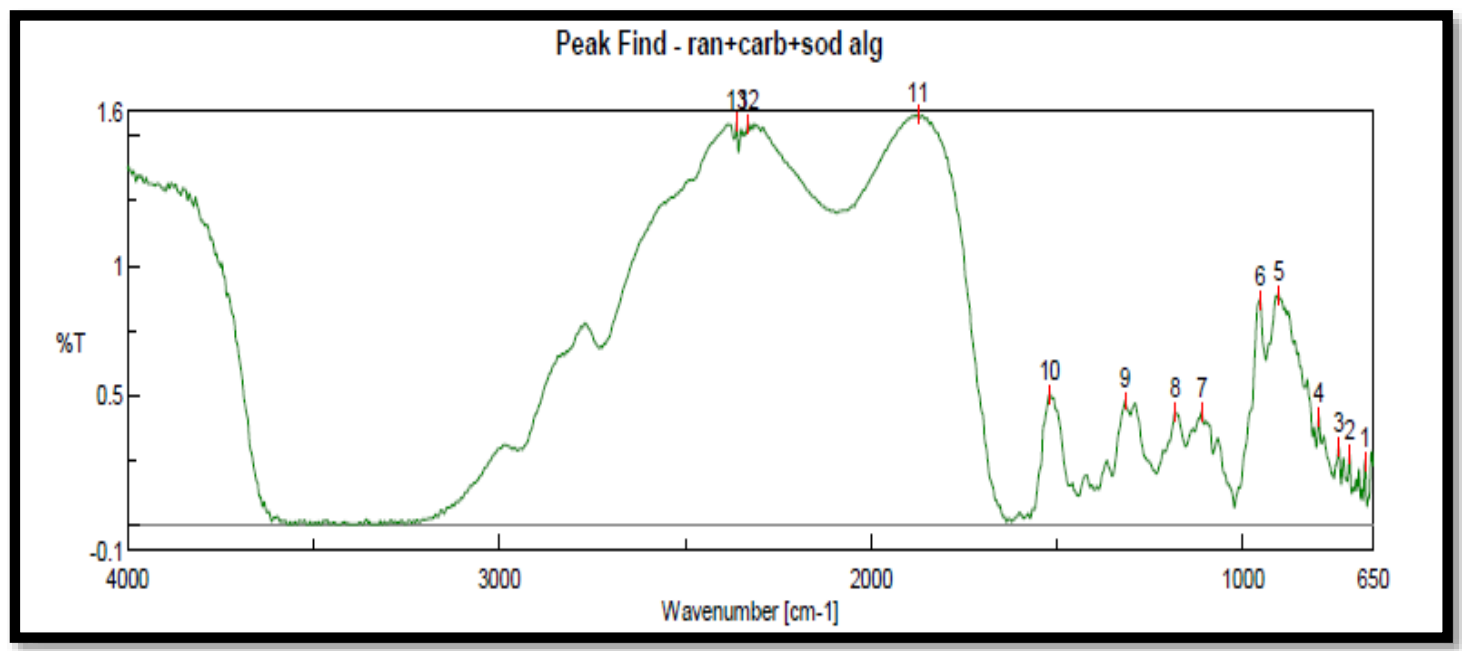

Fig. no 6: IR Spectra Studies of Physical Admixtures of Ranitidine hydrochloride, Carbopol 934 and Sodium Alginate. 


\section{International Journal of Current Science Research and Review}

ISSN: 2581-8341

\section{Volume 04 Issue 08 August 2021}

DOI: 10.47191/ijcsrr/V4-i8-01, Impact Factor: 5.825

IJCSRR@ 2021

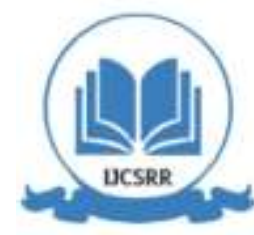

Www.ijcsrr.org

IR spectrums of the Ranitidine hydrochloride physical admixtures indicate that there is no interaction between the drug and polymers. The spectra can be simply regarded as the superposition of Ranitidine hydrochloride and polymers used for the preparation of microspheres. This observation ruled out the possibility of chemical interaction and complex formation between these components. It is concluded that the characteristics bands of pure drug were not affected after loading polymer microspheres and the drug was compatible within the physical admixtures. Hence drug excipient compatibility was established also which indicates the stable nature of drug during the entrapment Process

Characterization of Floating Microspheres

Percentage Yield and particle size

Table No 3: Percentage yield and average particle of Ranitidine hydrochloride floating Microspheres (RF)

\begin{tabular}{|l|l|l|}
\hline Formulations Code & Percentage Yield $(\boldsymbol{\%})$ & Average particle size $(\boldsymbol{\mu m})$ \\
\hline RF1 & $59.77 \pm 0.56$ & $131.4 \pm 0.56$ \\
\hline RF2 & $61.66 \pm 0.78$ & $150.23 \pm 4.195$ \\
\hline RF3 & $90.38 \pm 0.87$ & $168.2 \pm 1,963$ \\
\hline RF4 & $64.51 \pm 0.65$ & $119.90 \pm 1.831$ \\
\hline RF5 & $75.57 \pm 0.78$ & $125.74 \pm 2.119$ \\
\hline RF6 & $89.65 \pm 0.90$ & $135.24 \pm 1.742$ \\
\hline RF7 & $58.33 \pm 0.64$ & $99.92 \pm 1.221$ \\
\hline RF8 & $63.88 \pm 0.69$ & $100.35 \pm 2.221$ \\
\hline RF9 & $88.09 \pm 0.92$ & $103.70 \pm 0.321$ \\
\hline
\end{tabular}

Results are mean \pm S.D of three trials $(n=3)$

From the results it was observed that, the concentration of polymer increased, the percentage yield of the floating microspheres was also slightly increased.

\section{Morphological Studies}

The surface morphology of the microspheres were investigated and revealed by SEM for characterization of shape and size of floating microspheres and the surface view were shown in Photomicrograph 1 to 3.From the results, SEM indicated that the microspheres produced by RF3 formulation, are good specificity, spherical with smooth surface, uniform in shape and not aggregated which is responsible for the characteristic patterns of drug release.

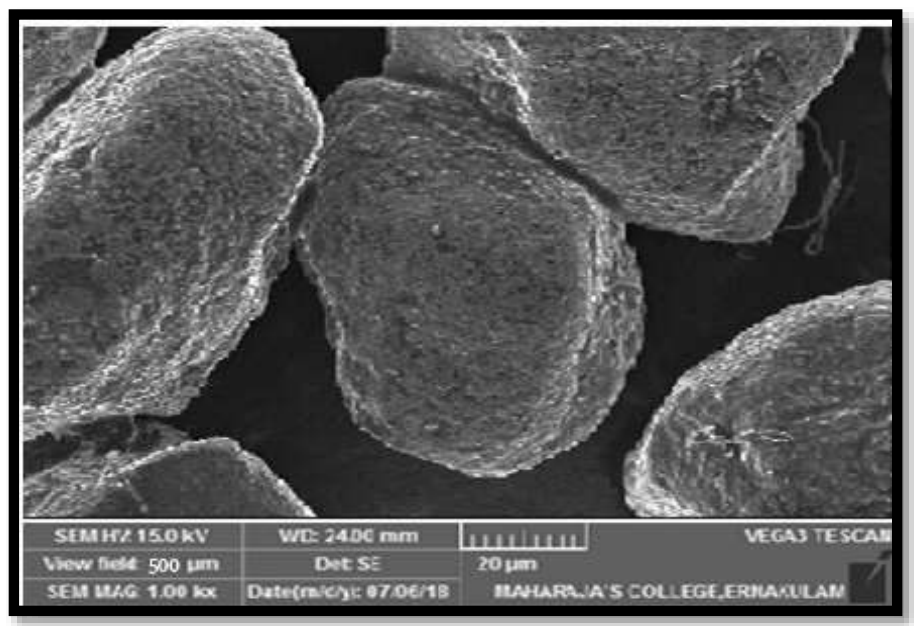

Fig.no. 7: Photo Micrograph-1(c) SEM Image of Ranitidine Hydrochloride Floating Microspheres (RF3)-Group 


\section{International Journal of Current Science Research and Review}

ISSN: 2581-8341

Volume 04 Issue 08 August 2021

DOI: 10.47191/ijcsrr/V4-i8-01, Impact Factor: 5.825

IJCSRR@ 2021

www.ijcsrr.org

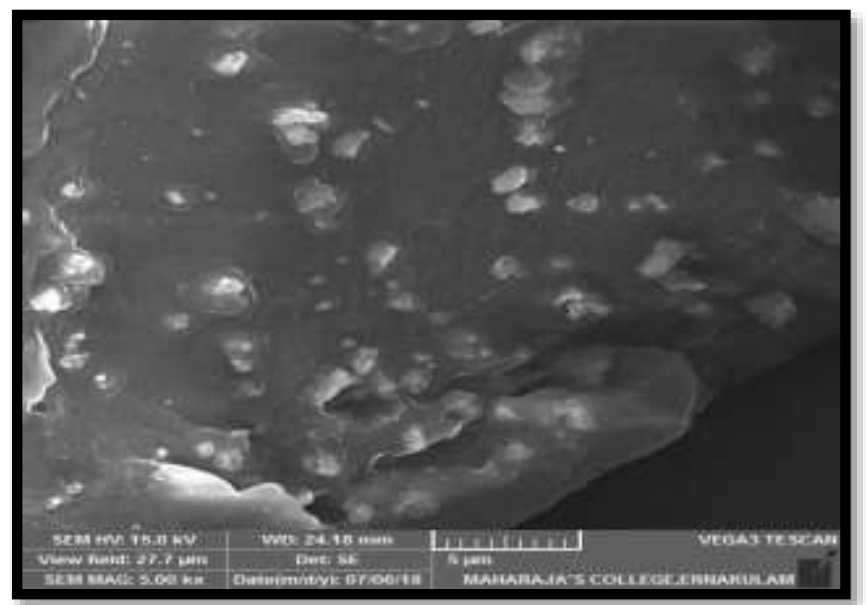

Fig. no. 8: Photo Micrograph-2(b) Surface morphology of

Ranitidine Hydrochloride Floating Microspheres (RF6)

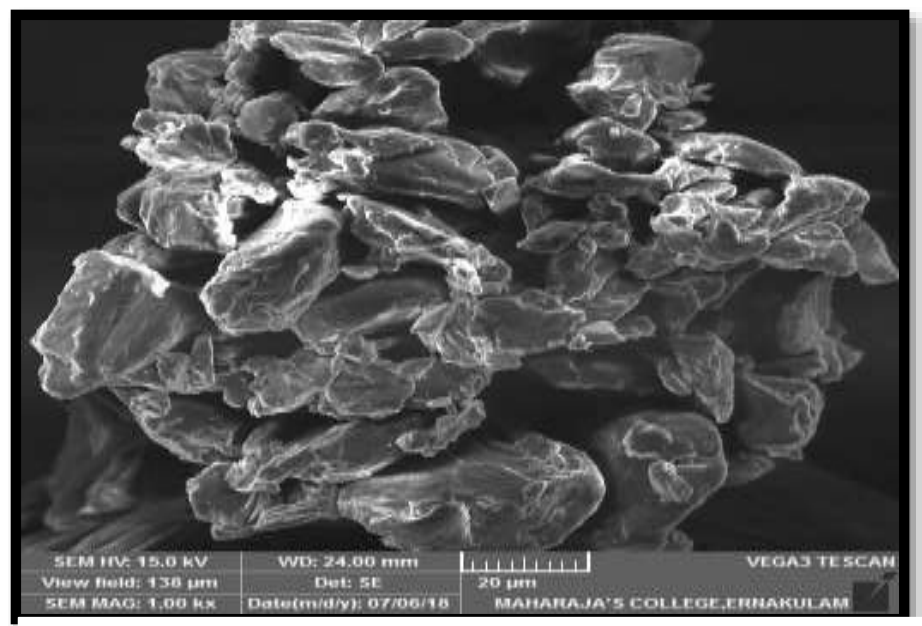

Fig.no. 9: Photo Micrograph-3(b)SEM Image of Ranitidine Hydrochloride Floating Microspheres (RF9)-Group

Micromeritic Properties

Bulk Density, Tapped Density, Carr's Index, Hausner's Ratio and angle of repose

The packing properties of the drug and their formulations are widely depending on bulk Density. It has been stated that bulk density less than $1.2 \mathrm{gm} / \mathrm{cm} 3$ indicate good flow and values greater than $1.5 \mathrm{gm} / \mathrm{cm} 3$ indicate poor flow. The result of bulk density, tapped density, Carr's index and Hausner's ratio were mentioned in table no 4.

Table No 4: Bulk density, Tapped density, Carr's index, Hausner's ratio and angle of repose values of Ranitidine Hydrochloride Floating Microspheres

\begin{tabular}{|l|l|l|l|l|l|}
\hline $\begin{array}{l}\text { Formulations } \\
\text { code }\end{array}$ & $\begin{array}{l}\text { Bulk density } \\
\left(\mathbf{g} / \mathbf{c m}^{\mathbf{3}}\right)\end{array}$ & $\begin{array}{l}\text { Tapped } \\
\text { density }\left(\mathbf{g} / \mathbf{c m}^{\mathbf{3}}\right)\end{array}$ & $\begin{array}{l}\text { Carr's index } \\
(\boldsymbol{\%})\end{array}$ & $\begin{array}{l}\text { Hausner's } \\
\text { ratio }\end{array}$ & $\begin{array}{l}\text { Angle of repose } \\
(\boldsymbol{\theta})\end{array}$ \\
\hline RF1 & $0.284 \pm 0.021$ & $0.345 \pm 0.087$ & $17.68 \pm 0.067$ & $1.21 \pm 0.091$ & $27.34 \pm 0.51$ \\
\hline RF2 & $0.664 \pm 0.052$ & $0.758 \pm 0.076$ & $12.00 \pm 0.076$ & $1.13 \pm 0.082$ & $28.61 \pm 0.58$ \\
\hline
\end{tabular}


ISSN: 2581-8341

Volume 04 Issue 08 August 2021

DOI: 10.47191/ijcsrr/V4-i8-01, Impact Factor: 5.825

IJCSRR@ 2021

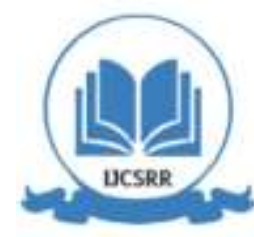

www.ijesrr.org

\begin{tabular}{|l|l|l|l|l|l|}
\hline RF3 & $0.712 \pm 0.021$ & $0.826 \pm 0.012$ & $13.80 \pm 0.065$ & $1.16 \pm 0.067$ & $29.51 \pm 0.64$ \\
\hline RF4 & $0.674 \pm 0.032$ & $0.790 \pm 0.067$ & $14.68 \pm 0.054$ & $1.17 \pm 0.058$ & $35.86 \pm 0.31$ \\
\hline RF5 & $0.368 \pm 0.045$ & $0.458 \pm 0.012$ & $19.65 \pm 0.023$ & $1.24 \pm 0.045$ & $37.92 \pm 0 . .43$ \\
\hline RF6 & $0.356 \pm 0.012$ & $0.414 \pm 0.046$ & $14.28 \pm 0.056$ & $1.13 \pm 0.013$ & $37.92 \pm 0.43$ \\
\hline RF7 & $0.682 \pm 0.034$ & $0.865 \pm 0.045$ & $18.30 \pm 0.043$ & $1.25 \pm 0.057$ & $36.57 \pm 0.51$ \\
\hline RF8 & $0.352 \pm 0.091$ & $0.410 \pm 0.012$ & $14.137 \pm 0.039$ & $1.16 \pm 0.094$ & $29.51 \pm 0.58$ \\
\hline RF9 & $0.457 \pm 0.087$ & $0.531 \pm 0.071$ & $15.93 \pm 0.089$ & $1.15 \pm 0.012$ & $31.47 \pm 0.64$ \\
\hline
\end{tabular}

Results are mean \pm S.D of three trials $(n=3)$

From the results, it was observed that the bulk density and tapped density values were lies between 0.284 to 0.712 and 0.345 to $0.865 \mathrm{~g} / \mathrm{cm}^{3}$ i.e., less than $1.2 \mathrm{gm} / \mathrm{cm}^{3}$ indicating good packing. The Carr's index was lies between $12 \%$ to $19.65 \%$ indicating excellent flow characteristics of floating microspheres. The Hausner's ratio was lies between 1.13 to 1.25 indicating good flow (Normal range: less than 1.25, while greater than 1.5 indicating poor flow). Angle of repose less than $40^{\circ}$ indicates free flowing properties of microspheres. However, angle of repose greater than $40^{\circ}$ indicates poor flow of material. It is observed that, the angle of repose for various ratios of the microspheres are found to be less than $40^{\circ}$ it indicates free flow properties of the floating microsphere.

\section{Determination of Entrapment Efficiency (EE)}

The amount of drug entrapped was estimated by crushing the specified quantity of microspheres and extracting with aliquots of $0.1 \mathrm{~N} \mathrm{HCl}(\mathrm{pH} 1.2)$ repeatedly. The amount of drug entrapped in the floating microspheres was shown in the Histogram as shown in Figure-27.

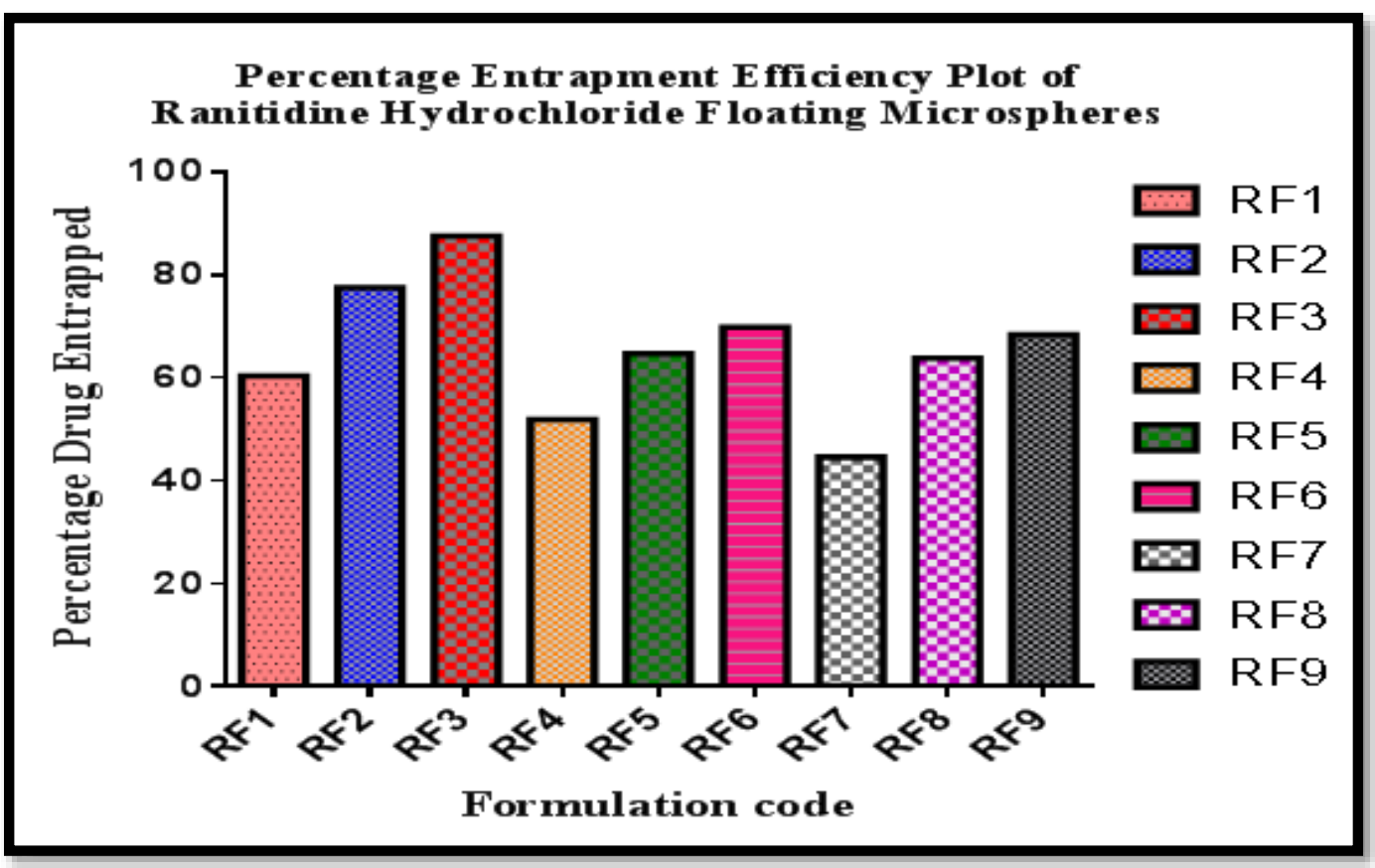

Fig.no. 10: Percentage entrapment efficiency of plot of Ranitidine Hydrochloride Floating Microsphere 


\section{International Journal of Current Science Research and Review}

ISSN: 2581-8341

Volume 04 Issue 08 August 2021

DOI: 10.47191/ijcsrr/V4-i8-01, Impact Factor: 5.825

IJCSRR@ 2021

WwW.ijcsrr.org

From the results, the percentage EE was found to be in the range $44.60 \%$ to $87.52 \%$ and specifically EE is more in formulations RF3, RF6 and RF9. Also it was observed that the EE of prepared microspheres is increased with increasing the polymer concentration. This is because as there is an increase in polymer concentration sufficient amount of polymer is present to entrap the drug, thus the EE is increased. When it was compared with three formulation RF3 shows best result (87.52\%) as compared to RF6 \&RF9.

\section{In-vitro Buoyancy Studies}

The percentage in-vitro buoyancy of floating microspheres of all the formulation was found in the range $66.92 \%$ to $81.52 \%$ after 12 hrs. The results of in-vitro buoyancy data are given in the histogram as shown in Figure-28.

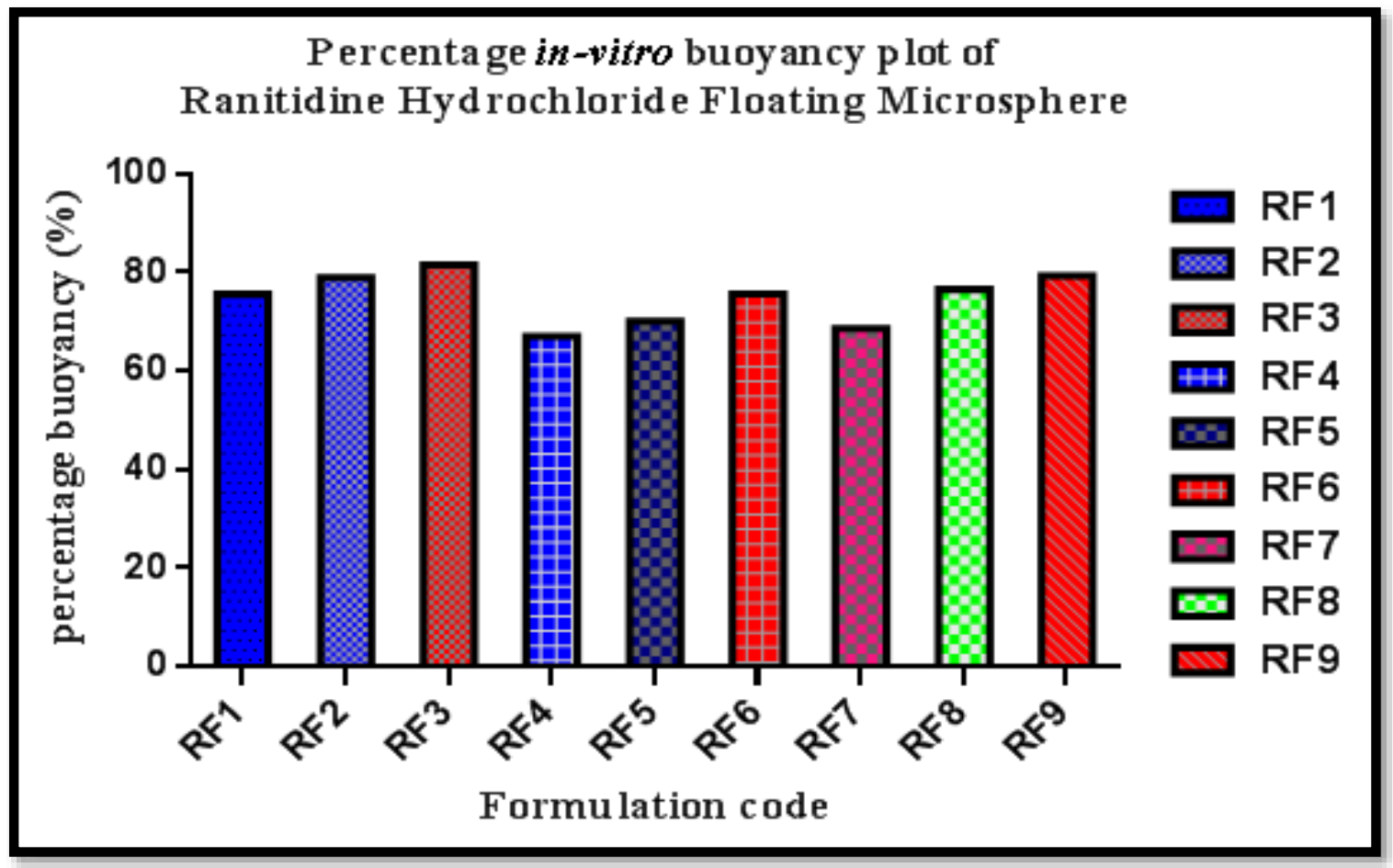

Fig.no. 11: Percentage in-vitro Buoyancy plot of Ranitidine Hydrochloride Floating microsphere

From the results, it was observed that the most of the microspheres in each formulation floated for prolonged period of time (12hrs) over the surface of the dissolution medium without any apparent Gelation. As the polymer concentration increases the buoyancy time also increases. So the in-vitro buoyancy of prepared floating microspheres (RF3) had shown high percentage floating than compared to other the other formulations.

\section{In-vitro Drug Release Studies}

Over all RF3 formulation (Method-I), RF6 formulation (Method -I) and RF9 formulation were having 89.97\%,92.91\% and 93.68\% drug releases the end of $12 \mathrm{hrs}$ when compared to all batches due to the increasing in polymer concentration. The increased concentration of polymers leads to increase in particle size and increase in density of polymer matrix into the microspheres which results in increased diffusion path length and consequently retardation of drug release due to the higher EE. Moreover, it is also clear that there is no burst release at initial hours and also exhibits prolonged and retard drug release at the end of the dissolution studies. 


\section{International Journal of Current Science Research and Review}

ISSN: 2581-8341

Volume 04 Issue 08 August 2021

DOI: 10.47191/ijesrr/V4-i8-01, Impact Factor: 5.825

IJCSRR@ 2021

www.ijesrr.org

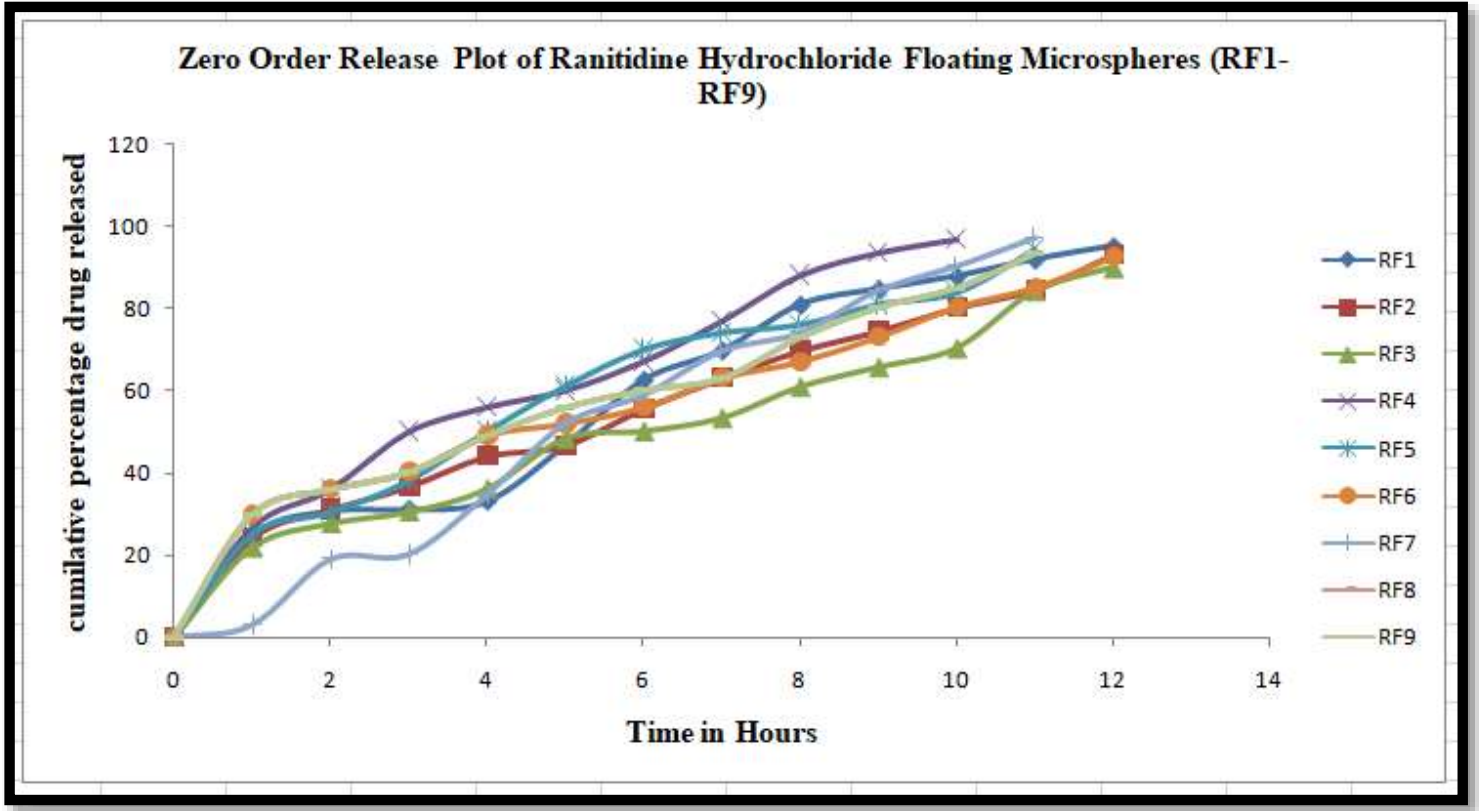

Fig.no.13: Zero order Plot of Ranitidine Hydrochloride Floating Microspheres (RF1-RF9)

In-vitro drug release kinetics

Table No 5: Kinetics Analysis of in-vitro drug release data of Ranitidine Hydrochloride floating microspheres (RF1-RF9)

\begin{tabular}{|c|c|c|c|c|c|c|c|c|}
\hline \multirow{3}{*}{$\begin{array}{l}\text { Formulations } \\
\text { Code }\end{array}$} & \multicolumn{8}{|c|}{ Release model } \\
\hline & \multicolumn{2}{|c|}{ Zero order } & \multicolumn{2}{|c|}{ First order } & \multicolumn{2}{|c|}{ Higuchi's } & \multicolumn{2}{|c|}{$\begin{array}{l}\text { Korsmeyer and } \\
\text { peppa's }\end{array}$} \\
\hline & $\mathbf{R}^{2}$ & $\$$ & $\mathbf{R}^{2}$ & $\mathbf{S}$ & $\mathbf{R}^{2}$ & $\mathbf{S}$ & $\mathbf{R}^{2}$ & $\mathbf{S}(\mathbf{n})$ \\
\hline RF1 & 0.877 & 3.360 & 0.860 & -0.057 & 0.889 & 21.64 & 0.749 & 0.875 \\
\hline RF2 & 0.904 & $\$ .051$ & 0.957 & -0.052 & 0.992 & 21.67 & 0.844 & 0.821 \\
\hline RF3 & 0.992 & 5.803 & 0.997 & -0.038 & 0.951 & 17.12 & 0.937 & 0.876 \\
\hline RF4 & 0.911 & 0.31 & 0.977 & -0.076 & 0.994 & 27.68 & 0.885 & 0.835 \\
\hline RF5 & 0.967 & 0.79 & 0.974 & -0.081 & 0.963 & 27.68 & 0.883 & 0.851 \\
\hline RF6 & 0.838 & 8.059 & 0.918 & -0.053 & 0.981 & 22.41 & 0.781 & 0.935 \\
\hline RF7 & 0.968 & 0.33 & 0.936 & -0.066 & 0.823 & 24.48 & 0.921 & 0.826 \\
\hline RF8 & 0.917 & .575 & 0.949 & -0.047 & 0.971 & 20.03 & 0.837 & 0.962 \\
\hline RF9 & 0.879 & $\$ .795$ & 0.952 & -0.061 & 0.987 & 23.95 & 0.809 & 0.941 \\
\hline
\end{tabular}

Regression coefficient $\left(\mathrm{r}^{2}\right)$, Slope $(\mathrm{s})$

The in-vitro drug dissolution data obtained was fitted to various mathematical Models such as zero order, First order, Higuchi matrix, and Krosmeyer Peppas model. The kinetic data analysis of all the formulations reached higher coefficient of determination with the first order $(\mathrm{R} 2=0.997)$. From the kinetics results the $\mathrm{n}$ values were found in the range between 0.821 to 0.962 with Regression coefficient values ranging from 0.749 to 0.937 indicating Non-Fickian diffusion mechanism i.e., Non-Fickian diffusion of drug through Ranitidine Hydrochloride floating microspheres. Hence, the above observations, the release of drug from floating microspheres provide a sustained for a period of sufficient hours and the kinetics study shows that' $\mathrm{r}^{2}$, values of all formulated batches indicate compliance with Higuchi's plot and which reveals that the drug release follows Non-Fickian diffusion mechanism (Korsmeyer-Peppa's mechanism) 


\section{International Journal of Current Science Research and Review}

ISSN: 2581-8341

Volume 04 Issue 08 August 2021

DOI: 10.47191/ijcsrr/V4-i8-01, Impact Factor: 5.825

IJCSRR@ 2021

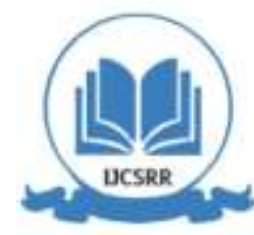

Www.ijcsrr.org

\section{Stability studies}

The optimized formulation of Ranitidine (RF3) was subjected to short term stability testing by storing the microspheres at room temperature $25^{\circ} \mathrm{C} / 60 \% \mathrm{RH}$ and also subjected to accelerated stability testing by storing the microspheres at temperature $40{ }^{\circ} \mathrm{C} / 70 \%$ RH. From the results, we observed there was no significant changes occurred in the drug content $(89.87 \%$ to $92.35 \%)$ and physical changes up to three months period of the stability study. This indicates a good stability of the prepared microspheres

\section{CONCLUSION}

It can be concluded that Floating Microspheres of Ranitidine Hcl were successfully prepared by ionotropic gelation and solvent evaporation technique. Among all the formulation optimized (RF3) formulation shown the very good drug release and fulfil all the evaluation parameters effectively. The microspheres were discrete, spherical with a central hollow cavity and showed sustained drug release patterns in simulated GI fluids. The drug entrapment efficiency, drug release and particle size of the microspheres were dependent on the concentration of polymers and stirring speed. The formulated microspheres floated in the simulated gastric fluid for over a period of $10 \mathrm{hrs}$. The Ranitidine Hcl loaded floating microspheres sustained drug release up to $12 \mathrm{~h}$; thereby, it could be capable of reducing the frequency of administration and the dose-dependent side effects with the repeated administration of conventional Ranitidine $\mathrm{Hcl}$ tablets. This type of sustained formulation will be better suitable for the patients. Thus, floating microspheres of ranitidine $\mathrm{Hcl}$ with good buoyancy and modified drug release were obtained.

\section{REFERENCES}

1. Banker Gilbert S, Rhodes Christopher T (1979) Modern Pharmaceutics. $4^{\text {th }}$ edn. Dekker Series, page: 291.

2. Londhe S, Gattani S, Surana S (2010) Development of Floating Drug Delivery System with Biphasic Release for Verapamil Hydrochloride: In vitro and In vivo Evaluation. Journal of Pharmaceutical Science and Technology 2: 361-367.

3. Baviskar P, Patil P and Saudagar RB: Floating drug delivery system: A comprehensive review. Journal of Drug Delivery and Therapeutics 2019; 9(3-s): 839-46.

4. Kandukoori NR, Shanthi MS, Sushma J, Ramya C, Swapna M, Madhu G, Deepika B, Rao KNV and Dutt RK: A review on floating drug delivery system. World Journal of Pharmaceutical Research 2017; 6(5): 553-68.

5. Hoffman A, Stepensky D, Lavy E, et al. (2004). Pharmacokinetic and pharmacodynamic aspects of gastroprotective dosage forms. Int J Pharm 277:141-53.

6. Grant SM, Langtry HD, Brogden RN: Ranitidine. An updated review of its pharmacodynamic and pharmacokinetic properties and therapeutic use in peptic ulcer disease and other allied diseases. Drugs. 1989 Jun;37(6):801-70.

7. Badillo R, Francis D: Diagnosis and treatment of gastroesophageal reflux disease. World J Gastrointest Pharmacol Ther. 2014 Aug 6;5(3):105-12.

8. Ajaykumar Tiwari,Gourange patel and Neerav Rabadia.Formulation and evaluation of floating microsphere $\mathrm{h} 2$ receptor blocker Ranitidine hcl by ionic Gelation method.International journal of pharmaceutical science and research.2012;vol 3(8):2801- 2808

9. Megha S, Seema K, Agnimitra D. In-vitro and in-vivo evaluation of repaglinide loaded floating microspheres prepared from different viscosity grades of HPMC polymer. Saudi Pharma J. 2015; 23: 675-682.

10. Sunil Kumar Prajapati (2014). Formulation and evaluation of novel stomach specific floating microspheres bearing famotidine for treatment of gastric ulcer and their radiographic study. Asian Pacific Journal of Tropical Biomedicine. Asian Pacific Journal of Tropical Biomedicine 4(9) 729-735.

11. Ashish A.Karhale,Sunil D Garande,Dheeraj T Baviskar,Dinesh K Jain.Design\&Evaluation of floating microsphere of Ranitidine Hydrochloride for gastro retentive drug delivery system, Indo American Journel of pharmaceutical Reserch, 2013; vol 3 issue 8:6066-6074.

12. Vinod Kumar, Pawan Jalwal1, Nirja, Jyoti, Tanuj Hooda, formulation and evaluation of floating microsphere of Ranitidine hydrochloride ,International journel of pharma professional Research. April 2014; vol 5,issue 2:1008-1015.

13. Sunit Kumar Sahoo, Abdul Arif Mallik, B .B. Barik, Prakash Senapati. Formulation and in-vitro evaluation of eudragit microspheres of Stavudin. Tropical Journal of Pharmaceutical Research.2005; 4(1): 369-375 


\section{International Journal of Current Science Research and Review}

ISSN: 2581-8341

Volume 04 Issue 08 August 2021

DOI: 10.47191/ijesrr/V4-i8-01, Impact Factor: 5.825

IJCSRR@ 2021

www.ijcsrr.org

14. Muniyandy Saravanana, Boddapati Anupama, Development and evaluation of ethylcellulose floating microspheres loaded with ranitidine hydrochloride by novel solvent evaporation-matrix erosion method, Carbohydrate Polymers 2011;82: 592598.

15. N. R. Kotagale, A. P. Parkhe, A. B. Jumde, H. M. Khandelwal And M. J. Umekar, Ranitidine Hydrochloride-Loaded Ethyl Cellulose And Eudragit RS 100 Buoyant Microspheres: Effect Of Ph Modifiers, Indian Journal of Pharmaceutical Sciences November - December 2011; 73 (6): 626-633.

16. Behera BC, Sahoo SK, Dhal S, Barik BB, Gupta BK. Characterization of glipizideloaded polymethacrylate microspheres prepared by an emulsion solvent evaporation method. Trop J Pharm Res 2008;7:879-85

17. Tanwar Y S, Naruka P S, Ojha G R. Development and Evaluation of Floating Microspheres of Verapamil hydrochloride. Brazilian Journal of Pharmaceutical Science 2007; 43(4): 529-534.

18. Alagasundaram M, Chetty MSC, Umashankari K. Microspheres as a novel drug delivery systems: A review. International Journal of Chem Tech Research. 2009;1(3): 526-34.

19. Prakash K, Sriram N (2012) Formulation and evaluation of mucoadhesive microspheres of pioglitazone hydrochloride prepared by solvent evaporation technique. International Journal of Biological \& Pharmaceutical Research 3: $1005-1015$.

20. Rani SB, Hari VBN, Reddy BA, Punitha S, Devi P, et al. (2010) The recent developments on gastric floating Drug delivery systems: an overview. Int J Pharm Tech Res 2: 524-534.

Cite this Article: Manikandan Palanivelu, Aswathi Prashob, Nethaji Ramalingam, Surendra Kumar Muniyandi (2021). Formulation and Evaluation of Ranitidine Hydrochloride Loaded Floating Microspheres for the Treatment of Gastric Ulcer. International Journal of Current Science Research and Review, 4(8), 833-845 